\title{
A Emenda Constitucional n.o 45/2004 e a nova competência da Justiça do Trabalho
}

Kátia Alessandra Pastori Terrin ${ }^{1}$

Prof. Dr. Lourival José de Oliveira

\section{Resumo}

Quando se menciona a competência da Justiça do Trabalho está-se referendando o poder que o órgão judicante tem de exercer jurisdição para processar e julgar os feitos segundo suas atribuições. Com a Emenda Constitucional no 45/04 a competência da Justiça do Trabalho sofreu significativa ampliação. Com esta modificação, diversas matérias, antes sujeitas à jurisdição comum, foram incorporadas por essa Justiça especializada. Com esta alteração constitucional, a nova competência material passa a abranger lides oriundas, não somente da relação de emprego, mas também as oriundas da relação de trabalho. Tal fato tem gerado diversos questionamentos acerca de algumas situações concretas dentro da realidade jurídica brasileira, merecendo um estudo mais aprofundado.

Palavras Chave: Justiça do Trabalho; Competência material; Emenda Constitucional no 45/04; Relação de emprego; Relação de trabalho.

\section{Introdução}

É imperativo reconhecer que a globalização da economia capitalista e os avanços tecnológicos e o aumento do desemprego, têm contribuído para exibir um panorama diversificado das formas de prestação de trabalho, alterando a forma do homem relacionarse com o meio na produção do trabalho.

Há por bem observar que a Justiça do Trabalho no Brasil, em suas origens, constituiu uma jurisdição especial, destinada a solucionar um conflito especial, mediante a aplicação de um direito material e um direito processual do trabalho. Evidente que essa foi e sempre será a missão por excelência da Justiça Obreira, que no seu nascedouro pretendia ser algo simples e célere, de forma a atender pleitos cuja natureza era alimentar, justificando-se talvez a sua constituição autônoma, no sentido de ser portadora de elementos próprios.

Acadêmica do 5o ano matutino do curso de Direito da Universidade Estadual de Londrina.

Doutor em Direito (PUC-SP); professor adjunto da Universidade Estadual de Londrina; professor da UNOPAR; professor da FACCAR; professor da UNIMAR. 
Todavia, a Justiça do Trabalho, como tudo na vida, precisava evoluir e acompanhar o dinamismo da sociedade, sob pena de soçobrar ante os novos ventos da modernidade, em especial no que diz respeito ao surgimento de novas formas de relações de trabalho.

É sobre este prisma que o presente trabalho se desenvolve, na medida que busca explicitar a ampliação da competência, trazendo à tona questões que estão gerando certos questionamentos no mundo jurídico, enquanto resposta à situação fática atual, no que se refere à amplitude das variações de relações de trabalho.

\section{Competência da Justiça do Trabalho}

A palavra competência deriva do latim "competentia" que significa estar em gozo ou no uso de, ser capaz, e possui na técnica jurídica uma dupla aplicação: tanto significa a capacidade, no sentido de aptidão pelo qual a pessoa pode exercitar ou fruir um direito; quanto à capacidade no sentido de poder, em virtude do qual a autoridade possui legalmente atribuição para conhecer de certos atos jurídicos e deliberar a seu respeito (PLÁCIDO E SILVA, 1999, p. 325).

Tem-se por competência a idéia de medida da jurisdição. É a competência que legitima o exercício de poder jurisdicional, e jurisdição é o poder que o juiz tem de dizer o direito nos casos concretos a ele submetidos (MARTINS, 2001, p. 114).

Nas palavras de Sérgio Pinto Martins (2001, p. 114), a competência vem a ser uma parcela da jurisdição de cada juiz. É a área geográfica e o setor do Direito em que cada juiz vai atuar, podendo emitir suas decisões. Consiste na delimitação do poder jurisdicional, sendo, portanto, o limite, a medida da jurisdição.

Sobre competência, Theodoro Júnior (2003, p. 141) explica que:

Como função estatal, é inegável que a jurisdição é una. No entanto, o exercício prático da jurisdição é realizado por diversos órgãos do Poder Judiciário. Assim, a competência é justamente o critério utilizado para distribuir as funções relativas ao desempenho da jurisdição entre os vários órgãos do Poder Judiciário.

Com base na Teoria Geral do Direito Processual, é possível formular inúmeros critérios para determinar a competência, levando-se em conta a matéria, a qualidade das partes, a função ou hierarquia do órgão julgador e o lugar. 
Quando se fala em competência da Justiça do Trabalho, está-se mencionando ou referendando o poder que o órgão judicante tem de exercer jurisdição para processar e julgar o feito, segundo as suas atribuições e segundo o interesse homogêneo, individual e difuso, em razão da matéria, da pessoa e do lugar, em decorrência da relação de trabalho individual ou coletivo (JESUS, 2006, p. 80).

Com a promulgação da Emenda Constitucional no 45, publicada no Diário Oficial em 31/12/04, houve significativa ampliação da competência da Justiça do Trabalho. Com esta ampliação, diversas matérias, antes sujeitas à jurisdição comum, foram incorporadas por esse ramo especializado, como é o caso, por exemplo, das ações sobre representação sindical ou das ações relativas às penalidades administrativas impostas aos empregadores pelos órgãos de fiscalização das relações de trabalho, dentre outras (SILVA, 2005, p. 1.321).

Da análise do artigo 114, anterior a Emenda em questão, conclui-se que o texto constitucional encerrava uma regra trina: competência material originária ou natural; competência material legal ou decorrente; e competência material executória (FILHO, 2006, p. 39).

A competência material originária ou natural nada mais era do que as atribuições da Justiça do Trabalho para conhecer e julgar os dissídios individuais e coletivos entre trabalhadores e empregadores. O que importava era a qualificação jurídica de "empregado" e "empregador", numa relação jurídica, para se delimitar a competência. Já a competência material legal ou decorrente entendia que para solucionar controvérsias decorrentes de outras relações diversas das relações de emprego, a Justiça do Trabalho só seria competente se houvesse expressa previsão em lei, e se a relação derivasse de uma relação de trabalho.

Com relação à competência material executória, manifestava-se pela competência executória das próprias sentenças. Contudo, tal competência foi substancialmente ampliada, antes mesmo da Reforma do judiciário, com a EC no 45/04.

Já com a nova redação, o artigo 114 especifica em nove incisos a nova competência trabalhista:

Art. 114. Compete à Justiça do Trabalho processar e julgar:

I as ações oriundas da relação de trabalho, abrangidos os entes de direito público externo e da administração pública direta e indireta da União, dos Estados, do Distrito Federal e dos Municípios;

Il as ações que envolvam exercício do direito de greve; 
III as ações sobre representação sindical, entre sindicatos, entre sindicatos e trabalhadores, e entre sindicatos e empregadores;

IV os mandados de segurança, habeas corpus e habeas data, quando o ato questionado envolver matéria sujeita à sua jurisdição;

V os conflitos de competência entre órgãos com jurisdição trabalhista, ressalvado o disposto no art. 102, I, o;

VI as ações de indenização por dano moral ou patrimonial, decorrentes da relação de trabalho;

VII as ações relativas às penalidades administrativas impostas aos empregadores pelos órgãos de fiscalização das relações de trabalho;

VIII a execução, de ofício, das contribuições sociais previstas no art. 195, I, a , e II, e seus acréscimos legais, decorrentes das sentenças que proferir;

IX outras controvérsias decorrentes da relação de trabalho, na forma da lei.

Abre-se aqui um parêntese para expor que durante os longos anos de tramitação da chamada reforma do judiciário, grande foi o empenho em defesa da ampliação do escopo de atuação da Justiça do Trabalho, para que viesse a dirimir todos os conflitos derivados das relações de trabalho e não apenas decorrentes da relação de emprego, como tradicionalmente ocorria (LORA, 2005, p. 193).

\section{Competência em razão da matéria}

A competência Ratione Materiae é a competência que se determina, ente juizes ou tribunais, em razão da ordem, da categoria e da natureza de sua jurisdição (PLÁCIDO E SILVA, 1999, p. 325).

Dispõe Sérgio Pinto (apud MARTINS, 2001, p. 115), que a competência em razão da matéria vai dizer respeito ao tipo de questões que podem ser suscitadas na Justiça Laboral, envolvendo a apreciação de determinada matéria trabalhista.

Contudo, é Carlos Henrique Bezerra Leite (2007, p. 180) quem melhor discorre sobre a competência material: "a competência em razão da matéria no processo do trabalho delimita em virtude da natureza da relação jurídica material deduzida em juízo".

Tem-se entendido que a determinação da competência material da Justiça do Trabalho é fixada em decorrência da causa de pedir e do pedido. Assim, se o autor da demanda relata que a relação material é regida pela CLT (Consolidação das Leis Trabalhistas) e formula pedidos de natureza trabalhista, cabe à Justiça do Trabalho processar e julgar referida demanda sendo esta também a orientação do STF (Supremo Tribunal Federal). 
João Orestes Dalazen (1992, p. 54) diz que o que dita a competência material da Justiça do Trabalho é a qualidade jurídica ostentada pelos sujeitos do conflito intersubjetivo de interesses: empregado e empregador, sendo que caso ambos comparecem a juízo como tais (empregado e empregador) inafastável será a competência desse órgão.

Com o advento da EC n. 45/04, a competência foi ampliada, de maneira que passa agora a processar e julgar as ações oriundas não apenas da relação de emprego, como também as oriundas da relação de trabalho.

Vale ressaltar que a incompetência em razão da matéria é de natureza absoluta e, portanto, deve ser declarada de oficio pelo juiz, independente de provocação das partes. Porém, cabe ao réu alegá-la antes de discutir o mérito, ou seja, em preliminar (art. 301, II, CPC).

O artigo 104, da CF, com a nova redação dado pela EC n.o 45/04, revela a existência de três regras de comportamento material: competência material original, competência material derivada e competência material executória. A titulo desse artigo, será analisada a competência material originária, e suas principais derivações, que vêm gerando vários questionamentos e dúvidas quanto à aplicação.

\subsection{Competência material original}

\subsubsection{Ações oriundas da relação de emprego}

A competência material original nada mais é do que a atribuição da Justiça do Trabalho para conhecer e julgar as lides oriundas da relação de emprego (LEITE, 2007, p. 181).

Essas lides são as que derivam das relações entre empregados e empregadores, ou seja, que surgem de um contrato individual de trabalho, ou das relações empregatícias coletivas. Há que se observar aqui que a expressão "relação de emprego" e "contrato de trabalho" são sinônimos, pois dizem respeito ao vínculo existente entre o empregado e o empregador, destacando-se o conceito de Délio Maranhão (1991, p. 271) de que o "contrato stricto sensu é o negócio jurídico pelo qual uma pessoa física se obriga, mediante pagamento de uma contraprestação, a prestar trabalho não eventual em proveito de outra pessoa, física ou jurídica, a quem fica juridicamente subordinado". 
Há de se destacar que as expressões "relação de trabalho" e "relação de emprego" não são sinônimos. A primeira compreende os chamados contratos de atividade, que são aqueles que apresentam um ponto em comum, qual seja, o objeto de todos eles consiste na utilização da energia humana e pessoal de um dos contratantes em proveito de outro. Já a segunda se distingue pela existência de subordinação jurídica do prestador de serviço ao tomador (LORA, 2005, p. 193).

Há por bem observar que juridicamente, todo o empregado é trabalhador, mas nem todo trabalhador é empregado. Diante disso, quer a relação de trabalho, quer de emprego, são relações jurídicas. A de emprego, porém, constitui modalidade especial da relação de trabalho, e foi em sua origem uma relação de direito real, sendo hoje de direito pessoal.

Vale destacar ainda que nas lides oriundas das relações de emprego, incluem-se todas as relações que figurem empregados urbanos ou rurais.

O fato é que a EC n. 45/04 atribui à Justiça do Trabalho a competência para apreciar e julgar as ações oriundas da relação de trabalho, o que ampliou consideravelmente a sua atuação, atribuindo-Ihe a prerrogativa de julgar os conflitos que emergem não apenas da relação de trabalho subordinada, mas também aqueles derivados da relação jurídica que tenha por objeto a prestação de serviço de uma determinada pessoa a um determinado destinatário.

\subsubsection{Dano moral}

Vale ressaltar que antes mesmo da promulgação EC n.․ 45/04, o STF, ao apreciar conflito de competência entre a Justiça Comum e a Justiça do Trabalho, já deixou pacificada que compete a essa última processar e julgar ação de indenização por dano moral que decorrer da relação de emprego. O que foi afirmado pelo TST (Tribunal Superior do Trabalho) na Súmula n.․ 392:

Dano moral. Competência da Justiça do Trabalho. Nos termos do artigo 114 da $\mathrm{CF} / 88$, a justiça do trabalho é competente para dirimir controvérsias diferentes à indenização por dano moral, quando decorrente da relação de trabalho.

É interessante destacar ainda que compete à Justiça do Trabalho o exame de ação de danos morais decorrentes de promessa de contrato de trabalho não cumprida pela 
empresa, conforme recente decisão da 3 Turma do TST. Embora, ainda se defenda a existência de um pré-contrato que não se encontra amparado pela competência da Justiça do Trabalho.

Ademais, Pamplona Filho $(2006$, p. 46) dispõe que as "ações de indenização por dano moral ou patrimonial nada mais são que postulações de responsabilidade civil", matéria que tem conteúdo interdisciplinar, envolvendo todos os ramos do Direito.

\subsubsection{Acidente de trabalho}

Primeiramente cumpre apontar que do acidente de trabalho decorrem duas possibilidades: a ação proposta em face do órgão previdenciário, objetivando indenização previdenciária e a ação em face do empregador, objetivando reparação civil pelos danos sofridos.

E vista da distinção entre a natureza das indenizações, cada uma delas tem sua competência diferentemente fixada. A competência para apreciar e julgar ações em face do órgão previdenciário é da Justiça Comum Estadual e está determinada pela exceção expressa no artigo 109, inciso I, da CF e pelo artigo 129, II, da Lei 8.213/91 (LORA, 2005, p. 196).

Já no que tange à Justiça do Trabalho, compete a ela julgar todos os dissídios entre trabalhadores e empregadores, sendo imperativa a conclusão que a reparação civil, por culpa ou dolo do empregador, na hipótese de infortúnio laboral, é um litígio que decorre da relação de emprego. Daí a competência da Justiça do Trabalho para apreciá-los.

Sobre a competência para apreciar ações envolvendo acidentes do trabalho, Carmo $(2005$, p. 2) ensina que:

Nenhum tema jurídico causou, após a vigência da Constituição Federal de 1988, tanto desconforto doutrinário e jurisprudencial quanto o da competência para apreciar ações envolvendo pedidos de indenização por danos morais e materiais decorrentes de acidente do trabalho. Antes da vigência da Carta Republicana de 1988, o tema era pacífico, porque o legislador constituinte sempre excepcionava taxativamente a competência da Justiça Comum para apreciar e julgar os dissídios envolvendo acidentes de trabalho. A diretriz era explícita: continuam na competência da Justiça Comum as causas que tenham como objeto pedidos conectados a acidentes do trabalho. Como na Constituição Federal de 1988 a regra exceptiva deixou de existir, a exegese em torno da competência para apreciar dissídios envolvendo acidentes de trabalho passou a ter regência exclusiva no artigo 109, item I, da Constituição Federal, assim vazado: Art. 109. Aos juízes federais compete processar e julgar : I- as causas em que a União, entidade autárquica ou empresa pública federal forem interessadas na condição de autoras, 
rés, assistentes ou oponentes, exceto as de falência, as de acidente do trabalho e as sujeitas à Justiça Eleitoral e à Justiça do Trabalho.

Da leitura dos ensinamentos de Carmo (2005, p. 3), entende-se que, antes da Constituição Federal de 1988 a competência para as ações envolvendo acidentes do trabalho era da justiça comum. Com o passar dos anos e com a entrada em vigor da Carta magna de 1988, a ordem legal que dava a referida competência à Justiça Comum largou de existir. Com a Constituição de 1988, passou a reger o assunto de forma exclusiva, apenas por meio do artigo 109, I da Constituição então em vigor. Observa-se que a Constituição estabelecia a competência ratione materiae à Justiça Comum, para tais demandas acidentárias. Acontece que, naquela época, alguns juizes discordando dos precedentes jurisprudenciais do STJ (Superior Tribunal de Justiça) e STF, defendiam, mesmo sem respaldo constitucional, que a competência seria da Justiça do Trabalho e não da Justiça Comum.

No entanto, se perfaz de extrema valia acrescentar que, em que pese esteja consagrado o entendimento de que as demandas que tratam da responsabilidade civil decorrentes de acidente de trabalho são de competência da Justiça Laboral, existem casos em que a competência será da Justiça Comum Estadual. Sendo este o caso da pretensão deduzida por parentes do trabalhador, postulando direito próprio com base na legislação constitucional comum, de natureza exclusivamente civil (LEITE, 2007, p. 187).

\subsubsection{Descontos previdenciários e fiscais}

É de competência da justiça do Trabalho processar e julgar a execução, de ofício, das contribuições sociais previstas no artigo 195, I, "a" e II da CF, e seus acréscimos legais decorrentes das sentenças que proferir (art. 114, VIII, CF), o que também foi pacificado na Súmula 368 do TST.

Ademais, foi editada a Lei n.o 10.035/00 que reafirma a competência da Justiça do Trabalho às questões relativas às contribuições previdenciárias que incidirem sobre as sentenças e acórdãos homologados por ela.

Um dos desafios da interpretação desse dispositivo esta na verificação dos seus limites, ou seja, a competência é apenas para o que se condenar, ou se abrange a possibilidade de condenação e execução em todas as contribuições previdenciárias decorrentes da relação de trabalho? 
Rodolfo Pamplona Filho (2006, p. 47) entende que se estenderia a todas, inclusive citando acórdão do TST, mesmo antes da EC n. o 45/04.

Contudo, Bezerra Leite (2007, p. 994) dispõe que somente as contribuições declaradas expressamente pela sentença trabalhista é que são de competência da Justiça do Trabalho.

O TST havia firmado o entendimento de que competiria à Justiça do Trabalho executar, inclusive de oficio, as contribuições decorrentes do reconhecimento do vínculo empregatício. É o que constava na Súmula 368. Porém, recentemente o Pleno do TST, por meio da Resolução no 138/05 resolveu alterar referida súmula em que limita-se às sentenças condenatórias.

\section{Ações oriundas da relação de trabalho}

Conforme já exposto, com a EC n. 45/04, a competência da Justiça do Trabalho foi significamente ampliada, e não mais se refere apenas as ações oriundas da "relação de emprego", mas também as ações oriundas da "relação de trabalho".

No entanto, é de extrema importância, a priori, fazer uma distinção entre relação de emprego e relação de trabalho.

A relação de trabalho é gênero da qual a relação de emprego seria apenas uma espécie. $O$ traço diferenciador entre os dois vínculos reside na subordinação, considerada no seu aspecto jurídico, ou seja, a existência de um poder ou direito de tomador do trabalho de dirigir e fiscalizar o serviço do obreiro inserido em uma atividade realizada em prol daquele (MENEZES; BORGES, 2005, p. 307).

É interessante não perder de vista que a CLT já admite, desde há muito, a competência da Justiça do Trabalho para apreciar litígios decorrentes de determinadas relações de trabalho, como do avulso (art. 643, caput e art. 652, V, da CLT), pequeno empreiteiro e artífice (art. 652, III, "a" da CLT), dentro da cláusula constitucional de 1946 que autoriza o legislador ordinário apreciar outras relações de trabalho, desde que autorizado por lei. (art. 142 da CF/46) (MENEZES; BORGES, 2005, p. 307).

Com a EC n.o 45/04, todas as ações oriundas da relação de trabalho, sem menosprezar os contratos civis, consumeristas ou outros contratos de atividade que serão melhor explanados a seguir, deverão ser ajuizados na Justiça do Trabalho. 
A nova regra de competência material toma por base a qualificação jurídica dos sujeitos envolvidos. O que importa para a delimitação da competência não é o tema discutido ou a legislação aplicada, mas sim a circunstância de versar a lide sobre questão ligada diretamente em uma relação de trabalho (FILHO, 2006, p. 43).

Não é novidade que a relação de trabalho é o gênero do qual a relação de emprego é espécie. Contudo, como enquadrar, por exemplo, as relações estatutárias? E a de consumo? E o trabalho gratuito? As dificuldades são inúmeras, mesmo porque o trabalho nos acompanha em quase todos os momentos da vida.

De acordo com o Projeto de Lei n. 6.671/02, em tramitação no Congresso, seriam de competência da Justiça do Trabalho as relações que envolvessem representante comercial autônomo e tomador de serviço; corretor e tomador de serviço, transportador autônomo e a empresa de transporte ou usuário do serviço; empreiteiro e subempreiteiro parceiro ao arrendatário rural e proprietário; cooperativa de trabalho e associados, dentre outros.

Marcio Túlio Viana (2005, p. 687) diz que mesmo se aprovado o projeto, o rol deve ser considerado exemplificativo. De outro modo, a lei ordinária estaria reduzindo à norma constitucional.

Cláudio Armando de Menezes e Leonardo Dias Borges (2005, p. 312) elencam que nem todo labor humano ensejará uma relação de trabalho, pois esta pressupõe uma relação jurídica, isto é, um vínculo estabelecido entre sujeitos de direito, formando a partir de um fato, ao qual o sistema jurídico atribui a produção de determinados efeitos.

\subsection{Relação de trabalho avulso, eventual e autônomo}

O obreiro chamado avulso, nas palavras de Maurício Godinho Delgado (2006, p. 341), corresponde à modalidade de trabalhador eventual, que oferta sua força de trabalho, por curtos períodos de tempo, a distintos tomadores, sem se fixar especificamente a qualquer deles. O que o distingue, entretanto, do trabalhador eventual, é a circunstância de sua força de trabalho ser ofertada através de uma entidade intermediária.

É competência originária da Justiça do Trabalho processar e julgar as ações oriundas da relação de trabalho avulso (art. 114, I, CF), bem como conciliar e julgar lides derivantes dessa relação (art. 643, CLT). Além de ser de sua competência apreciar as ações propostas 
pelo trabalhador avulso em face do sindicato da correspondente categoria profissional, por força do artigo 114, III da CF. Vale ressaltar que aqui se trata de competência em razão da pessoa e não da matéria (LEITE, 2007, p. 205).

Já a relação de trabalho eventual, apresenta uma das figuras de prestadores de trabalho que mais se assemelha ao empregado. Nela estão presentes pressupostos da relação empregatícia, não se apresentando, contudo, o elemento permanência.

De maneira geral, é trabalhador quem presta serviços ao tomador, subordinadamente e onerosamente e em regra também com pessoalidade, no entanto, ausente o pressuposto da não-eventualidade (DELGADO, 2006, p. 339).

A princípio, vale ressaltar que o trabalho eventual não é tutelado pelo direito material do trabalho, conforme se observa da leitura do artigo 3 a CLT que exige a nãoeventualidade como uma característica da relação de emprego.

Dessa forma, as lides decorrentes da relação de trabalho eventual seriam, por exclusão, dirimidas pela Justiça Comum, uma vez que não existe lei prevendo expressamente a competência da Justiça do Trabalho, como exige o texto original do artigo 114 da CF.

Contudo, por força do inciso I do referido artigo, se o autor alega que era trabalhador eventual e pede indenização pelos serviços prestados ao respectivo tomador, por se tratar de uma ação oriunda de relação de trabalho, a competência será da Justiça Obreira (LEITE, 2007, p. 205).

Com relação ao trabalhador autônomo, tem-se a figura do trabalhador que desempenha seus serviços de forma não subordinada ao tomador, bem como ausente o caráter de pessoalidade na prestação laboral.

A empreitada, a locação de mão-de-obra, também conhecida como prestação de serviço, e o mandato, regulados pelo Código Civil, são espécies de relação de trabalho autônomo, porém não se aplicam normas materiais da CLT. E a princípio eram de competência da Justiça Comum. No entanto, com a EC n. 45/04, passaram a ser de competência da Justiça do Trabalho, por força do artigo 114, inciso I da CF.

José Antonio R. de Oliveira Silva (2005, p. 320) diz que no direito comum a prestação de trabalho ainda hoje é objeto dos contratos de empreitada (arts. 610 a 626, C.C). Em ambos, o prestador de serviços ou empreiteiro tem autonomia, não se subordinando a uma organização empresarial do tomador de serviços. E desde muito, a 
Justiça do Trabalho tem competência material para solucionar as lides dos pequenos empreiteiros, hipótese prevista no artigo 652, alínea "a", do inciso III da CLT.

E conclui afirmando que desde que haja continuidade na prestação do serviço, seja por operário ou artífice da empreitada, seja por prestador de serviços, como faxineiro, jardineiro, limpador de piscinas, a competência para a solução das lides decorrentes da relação de trabalho será da justiça especializada (SILVA, 2005, p. 320).

\section{Contratos afins}

É importante observar as relações jurídicas derivadas de alguns contratos que têm estrita ligação com os de empreiteira ou de prestação de serviços. Trata-se dos contratos de representação comercial, de corretagem, de transporte, de parceria e de prestação de serviço em regime de cooperativa.

\subsection{Representação comercial}

O primeiro deles é o que mais de aproxima de contrato de emprego no setor privado. Possui institutos comuns às relações jurídicas oriundas de ambos os contratos, como contrato por prazo determinado ou indeterminado, indenização pela rescisão do contrato, pagamento de comissões, aviso prévio, dentre outros. Isso demonstra a dificuldade do juiz do trabalho em quase todas as ações ajuizadas por representante postulando a declaração de vinculo empregatício com o representado (SILVA, 2005, p. 321).

Há que se observar que, muito embora exista a proximidade das relações de trabalho do representante comercial e do empregado, as relações de representantes com o representado são relações de trabalho stricto sensu.

O artigo 39 da Lei n.o 4.886/65, que regula atividades dos representantes comerciais autônomos, dispõe que compete à Justiça Comum julgar controvérsias decorrentes dessa relação. No entanto, referido artigo remete-se aos casos de representante pessoa jurídica, com uma organização empresarial para atuação. Já o representante comercial, mesmo que devidamente inscrito no Conselho Regional, o que é obrigatório, e mesmo que preste serviço por intermédio de firma de representação terá 
direito de reclamar seus haveres perante a Justiça do Trabalho, por força do artigo 114, inciso I da Carta Magna (SILVA, 2005, p. 323).

Aqui o critério para definição da competência é a continuidade da prestação de serviço, presente no próprio conceito de representante comercial, dado pelo artigo 1으 da Lei ก.ㅇ 4.886/65.

\subsection{Contrato de corretagem}

Observa Amauri Mascaro Nascimento (2001, p. 227) que a corretagem não é um contrato de atividade, mas sim de resultado, pois só haverá pagamento de comissão se for concluído o negócio. Referido contrato se encontra regulado pelos artigos 722 a 729 do Código Civil.

Havendo continuidade na prestação de serviços de corretagem de imóveis (Lei n.o 6.530/78), haverá relação de trabalho entre as partes, no caso, por exemplo, de corretor que trabalho em dias ou horários determinados, cumprindo plantões ou não. Estes terão seus conflitos dirimidos pela Justiça do Trabalho (SILVA, 2005, p. 321).

\subsection{Contrato de transporte}

O contrato, escrito ou verbal, de transporte pode ser instantâneo ou de prestação continuada. José Antônio de Oliveira Silva (2005, p. 322) entende que somente na segunda hipótese enseja uma relação de trabalho entre o transportador e as pessoas que o contratarem, posto que no primeiro caso há uma relação de consumo e não tomadores e trabalho.

Destarte, não é critério do destinatário final que distingue a relação de trabalho da relação de consumo de serviço, pois tanto faz o motorista de alunos ter sido contratado pela escola, quanto pelos pais, haverá relação de trabalho, já que não há diferença substancial no modo da prestação do serviço, bastando a continuidade do serviço de transporte para que o motorista possa ajuizar ação perante a Justiça especializada (SILVA, 2005, p. 322). 


\subsection{Contrato de parceria}

Com relação aos contratos de parceria, dentre eles o arrendamento peculiar do meio rural, embora não tenha ido tratado pelo novo Código Civil, ainda remanesce no mundo jurídico. Diante disso, José António de Oliveira (apud SILVA, 2005, p. 322) afirma que não se trata de relação de consumo, sendo competente a justiça do Trabalho para conhecer e julgar as lides que surgirem entre os parceiros.

\subsection{Contrato de prestação de serviço em regime de cooperativa}

Tomemos como exemplo uma cooperativa de médicos. A relação entra a cooperativa e os contratantes de serviços, ou ainda, do próprio médico com o seu cliente, é uma relação de consumo. Todavia, a relação entre médico e a cooperativa, ou entre ele e determinado hospital onde os serviços são prestados, será uma relação de trabalho, presente a continuidade nas prestações, sendo, portanto, competente a Justiça do Trabalho.

\subsection{Relação de trabalho no âmbito da administração pública}

No que tange as causas que envolvem os servidores públicos estatutários ou sujeitos de vinculo administrativo especial de um lado e os entes federativos de outro, há que se observar que desde 1989 a jurisprudência da Suprema Corte tem se dado no sentido de excluir da competência da Justiça do Trabalho as lide dos servidores públicos, acrescentando a ADIn ajuizada contra o artigo 240, alínea "d" e da Lei n.o 8.112/90 onde o STF declarou inconstitucional tais dispositivos legais, entendendo que os servidores públicos civis da União têm origem estatutário e por isso não têm direito de ajuizar ação perante a Justiça do Trabalho. E nos níveis estadual e municipal há súmula do STJ no sentido de que a competência e da Justiça Comum Estadual (Súmula 137).

Contudo, com a EC n.․ 19/98, foi alterado o artigo 39, caput, da Constituição Federal, não havendo mais obrigatoriedade de a União, os Estados, o Distrito Federal e os Municípios terem regime jurídico único para os servidores, podendo contratar por regime celetista, sendo que a competência será, portanto, da Justiça do Trabalho (LEITE, 2007, p. 212). 
Observa-se que os servidores públicos submetidos a regime estatutário regular ou regime administrativo especial, incluindo aqui os servidores públicos temporários, matem com o poder publico relação jurídica institucional ou de caráter administrativo, não tendo relação de trabalho stricto sensu com os entes da Federação (SILVA, 2005, p. 311).

Vale destacar ainda que recentemente o TST decidiu que compete à Justiça do Trabalho anular acordo coletivo de servidor público ainda que regido por estatuto próprio.

Ademais, no que concerne à relação empregatícia existente no âmbito das empresas públicas e sociedades de economia mista, a competência da Justiça do Trabalho está implícita no inciso I do artigo 114 da CF (LEITE, 2007, p. 219).

\section{Relação de consumo}

Tendo em vista as várias definições de relação de trabalho até aqui dispostas, abrese agora um parêntese para discorrer sobre a relação de consumo.

A relação de trabalho é gênero tão amplo que não é possível que o legislador constitucional derivado tenha cometido o desatino de remeter à apreciação de uma justiça especializada todo gênero de trabalho humano (SILVA, 2005, p. 317).

A relação de trabalho em sentido lato haverá em toda prestação de serviço precedida de um contrato formal ou simples ajuste entre as partes.

Se os serviços forem oferecidos no mercado de consumo e o tomador puder ser identificado como consumidor, não haverá uma relação estrita de trabalho, mas sim uma relação de consumo.

Ensina Bezerra Leite (2007, p. 206) que não são de competência da Justiça do Trabalho as ações oriundas da relação de consumo. Isso porque relação de trabalho e de consumo não se confunde.

No entendimento de José Affonso Dallegrave Neto (apud SILVA, 2005, p. 317), a grande distinção entre relação de trabalho e a de consumo de serviços recorrem ao teor dos artigos 2으 e 3으 do Código de Defesa do Consumidor (Lei n. 8.078/90), definindo que os serviços oferecidos no mercado de consumo e usufruídos por um destinatário final ensejam uma relação de consumo, não se tratando de relação de caráter trabalhista.

Faz-se necessário distinguir consumidor de tomador de serviços. Utilizando-se do artigo 2 ㅇ do $C D C$, consumidor é a pessoa física ou jurídica que adquire ou utiliza produto ou 
serviço como destinatário final. Já o tomador, para a relação de trabalho, é a pessoa física ou jurídica que utiliza os serviços prestados por um trabalho autônomo como intermediário (LEITE, 2007, p. 206).

Nas relações de consumo pressupõe dois pólos de interesse: consumidorfornecedor e a coisa, objeto que tanto pode ser um produto como um serviço.

Consumidor, portanto, é a pessoa que, inserida no mercado de consumo, efetua aquisições de bens ou contrata a prestação de serviços, na condição de destinatário final. Fornecedor, por sua vez, é qualquer pessoa física ou jurídica que oferta aos consumidores produtos ou serviços (LORA, 2005, p. 194).

Sempre que o fornecedor de serviço for pessoa física que presta atividade laboral a outra pessoa, física ou jurídica, estar-se-á diante de um contrato de atividade. A prestação pode ser a título subordinado, de forma autônoma, ou ainda, se tratar de trabalhador parasubordinado. Qualquer que seja a modalidade de relação de trabalho, havendo litígio, o juízo competente será a Justiça trabalhista (LORA, 2005, p. 195).

\section{Competência material derivada}

Além da competência material original (art. 114) a Constituição Federal outorga também à Justiça do Trabalho a competência material derivada (art. 114, inciso IX, CF), segundo a qual compete à Justiça Obreira processar e julgar "outras controvérsias decorrentes da relação de trabalho, na forma da lei".

É imprescindível, portanto, que haja a existência de uma lide decorrente da relação de trabalho, bem como a existência de lei prevendo expressamente que a competência para apreciar esta lide seja da Justiça do Trabalho.

Se houver lei dispondo que a controvérsia oriunda da relação de trabalho determinada é da competência da Justiça Comum, com esta permanecerá até que sobrevenha lei transferindo para a Justiça do Trabalho (LEITE, 2007, p. 222).

Todavia, diante da lentidão da edição da norma regulamentadora, tudo indica que se consolidará o entendimento de "derivação". Ou seja, que independente de norma regulamentadora, tendo a lide liame lógico com a relação de trabalho, será da Justiça laboral a competência. 


\section{Conclusão}

Diante de todo o exposto, há por bem reiterar que a significativa abrangência trazida pela EC no 45/04, modificando assim a competência da Justiça do Trabalho, introduziu alguns avanços na disciplina da competência material. Cabe agora à Justiça do Trabalho, que tanto lutou para implementar a Reforma do Poder Judiciário, reformar-se para cumprir a notável missão a ela investida, uma vez que o seu campo de atuação foi ampliado, tornando-a consequentemente mais forte, reclamando um constante e rápido amadurecimento por parte dos seus componentes.

\section{Referências}

BARROS, Cássio Mesquita. A Reforma Judiciária da Emenda Constitucional. Revista LTr, São Paulo, n. 3, p. 274, mar. 2005.

BEBBER, Júlio César. Nova competência da Justiça o trabalho e Regras Processuais. Revista LTr, São Paulo, n. 3, p. 312, mar. 2005.

CARMO, Júlio Bernardo do. Da competência da Justiça do Trabalho para apreciar e julgar pedidos de indenização por danos materiais e morais decorrentes de acidente de trabalho. Competência absoluta ou condicionada?. Jus Navigandi, Teresina, v. 9, n. 736, 11 jul. 2005. Disponível em: <http://jus2.uol.com.br/doutrina/texto.asp?id=6990>. Acesso em: 10 de Abril de 2007.

DALAZEN, João Orestes. Indenização civil de empregado e empregador por dano patrimonial ou moral. Revista de Direito do trabalho, São Paulo, n. 77, p. 54, mar. 1992.

DELGADO, Maurício Godinho. Curso de Direito do Trabalho. 5. ed. São Paulo: LTr, 2006.

FILHO, Rodolfo Pamplona. A nova competência da Justiça do Trabalho. Uma compreensão dos limites do novo artigo 114 da Constituição Federal de 1988. Revista LTr, São Paulo, v. 70, n. 1, p. 39, jan. 2006.

GIGLIO, Wagner D. Nova Competência da Justiça do Trabalho: Aplicação do Processo Civil ou Trabalhista? Revista LTr, São Paulo, v. 69, n. 3, p. 290, mar. 2005.

JESUS, Ricardo Henrique de. A competência da Justiça do Trabalho nos parâmetros do artigo 114 da Constituição com a redação da atual EC no 45/04. Revista LTr, São Paulo, v. 70, n. 1, p. 167, jan. 2006. 
LEITE, Eduardo Oliveira. Curso de Direito Processual do Trabalho. 5. ed. São Paulo: LTr, 2007.

LORA, Ilse Marcelina Bernardi. A nova competência da Justiça do Trabalho. Revista LTr, São Paulo, v. 60, n. 2, p. 195, fev. 2005.

MAIOR, Jorge Luiz Souto. Em defesa da Ampliação da Justiça do Trabalho. Revista LTr, São Paulo, v. 70, n. 1, p. 13, jan. 2006.

MARANHÃO, Délio. Instituições de direito do trabalho. 12. ed. São Paulo: LTr, 1991.

MARTINS, Sérgio Pinto. Direito Processual do Trabalho. 17. ed. São Paulo: Atlas, 2001.

MENEZES, Cláudio Armando; BORGES, Leonardo Dias. A Emenda Constitucional no 45 e algumas questões a cerca da competência e do procedimento na Justiça do Trabalho. Revista LTr, São Paulo, v. 69, n. 1, p. 300, mar. 2005.

NASCIMENTO, Amauri Mascaro. Curso de Direito do Trabalho. 16. ed. São Paulo: Saraiva, 2001.

PLÁCIDO e SILVA. Vocabulário Jurídico. 15. ed. Rio de Janeiro: Editora Forense, 1999.

SILVA, Luís Carlos Cândido Martins Sotero. A nova competência da Justiça do Trabalho e as súmulas do Superior Tribunal de Justiça. Revista LTr, São Paulo, v. 69, n. 11, p. 317, nov. 2005.

THEODORO JUNIOR, Humberto. Curso de direito processual civil. 43. ed. Rio de Janeiro: Forense, 2003. 3 v. 